\title{
Inflammatory osteolysis: a conspiracy against bone
}

\author{
Gabriel Mbalaviele, ${ }^{1}$ Deborah V. Novack, ${ }^{1,2}$ Georg Schett, ${ }^{3}$ and Steven L. Teitelbaum ${ }^{1,2}$ \\ 'Department of Medicine, Division of Bone and Mineral Diseases, and 'Department of Pathology and Immunology, Division of Anatomic and Molecular Pathology, Washington University School of Medicine, \\ St. Louis, Missouri, USA. ${ }^{3}$ Department of Internal Medicine 3, Rheumatology and Immunology, University of Erlangen-Nuremberg, Erlangen, Germany.
}

\begin{abstract}
There are many causes of inflammatory osteolysis, but regardless of etiology and cellular contexts, the osteoclast is the bone-degrading cell. Thus, the impact of inflammatory cytokines on osteoclast formation and function was among the most important discoveries advancing the treatment of focal osteolysis, leading to development of therapeutic agents that either directly block the bone-resorptive cell or do so indirectly via cytokine arrest. Despite these advances, a substantial number of patients with inflammatory arthritis remain resistant to current therapies, and even effective anti-inflammatory drugs frequently do not repair damaged bone. Thus, insights into events such as those impacted by inflammasomes, which signal through cytokine-dependent and -independent mechanisms, are needed to optimize treatment of inflammatory osteolysis.
\end{abstract}

\section{Introduction}

The skeleton is a dynamic organ that normally maintains its mass by collateral osteoblast activity despite constant removal of effete bone by osteoclasts. Commonly, in states of hormonal deficiency and aging, this balance is compromised as resorption supersedes formation, resulting in global loss of bone. Fortuitously, available and effective osteoporotic therapies are able to enhance systemic bone mass and reduce fracture risk in aging individuals and postmenopausal women.

Inflammatory diseases that affect joints, skin and the gut including rheumatoid arthritis (RA), psoriatic arthritis (PsA), and Crohn's disease - also promote bone loss that is often severe (1-3). Inflammation-driven bone degradation affects the axial and appendicular skeleton early in life and enhances the risk of fracture. Even when not profound, inflammation increases fracture risk, underscoring its skeletal relevance $(4,5)$.

When inflammation occurs in the vicinity of bone, such as in RA, PsA, orthopedic implant-associated osteolysis, and osteomyelitis, it induces focal erosion that is often devastating. Although major medical achievements have improved the treatment of inflammatory arthritides, limitations remain, such as resistance to therapy in more than one third of RA and PsA patients and failure to restore damaged bone (6). Thus, further understanding of the pathogenesis of various forms of focal osteolysis is necessary to provide a foundation for their prevention and cure.

Immune cells and their products influence the activities of osteoclasts, osteoblasts, and osteocytes to dictate bone mass and strength. This relationship of the immune and skeletal systems was suggested more than 40 years ago by the discovery that stimulated monocytes produce a catabolic, bone resorption-promoting factor that was subsequently proven to be $\operatorname{IL}-1 \beta(7,8)$. These observations and others, including the discovery of the key osteoclastogenic cytokine, RANKL (9), prompted the discipline of osteoimmunology. In consequence, studies of the means by which cytokines such as

Conflict of interest: C. Mbalaviele is co-founder of Confluence Life Sciences Inc. Reference information: / Clin Invest. 2017;127(6):2030-2039. https://doi.org/10.1172/JCI93356.
TNF- $\alpha$, IL-1 $\beta$, and IL-17 impact bone cells have provided insights into the mechanisms of the osteolysis of RA and PsA and improved the success of cytokine-inhibiting biological drugs in reducing the crippling peri-articular complications of these diseases. Osteoimmunology has also revealed that postmenopausal osteoporosis reflects an interplay between estrogen deficiency and immune activation (10). Given the excellent reviews on these topics, we will not address the role of inflammation in the pathogenesis of systemic bone loss (11).

\section{Osteoclasts are the principal effectors of inflammatory osteolysis}

While resident mesenchymal and immune cells participate in inflammatory bone destruction, the effector cell of focal osteolysis is the osteoclast, the product of myeloid/macrophage precursor fusion (12). In physiological conditions, osteoclast formation is dictated by the interaction of RANKL, a member of the TNF superfamily, with its receptor RANK (9). Interestingly, whereas high-dose RANKL is potently osteoclastogenic, low-dose RANKL may actually increase bone formation (13).

RANK activation by RANKL depends upon cytokine-mediated trimerization of the receptor in a TNF receptor-associated factor 6-dependent (TRAF6-dependent) manner (14-16). RANKL/ RANK signaling induces MAP kinases and NF- $\kappa \mathrm{B}$, eventuating in the activation and expression of NFATc1, the key osteoclastogenic transcription factor (17-20). Elevation of RANKL abundance, which is typically the crucial event regulating bone resorption, is negatively regulated by osteoprotegerin (OPG) (21-23), a decoy receptor with a higher affinity for the osteoclastogenic cytokine than that of RANK; thus, RANKL binding to OPG effectively limits osteoclastogenesis $(9,15)$. In fact, loss-of-function OPG mutations prompt a severe generalized osteolytic disorder known as juvenile Paget's disease (24). Macrophage colony-stimulating factor (M-CSF) is also essential for osteoclast formation, exerting its effects by signaling via its receptor, C-FMS (25).

The magnitude of bone degradation depends upon both the number of osteoclasts and their individual resorptive capacity. As stated above, physiological osteoclast abundance is dictated principally by RANKL, M-CSF, and OPG, which are modulated by cytokines 


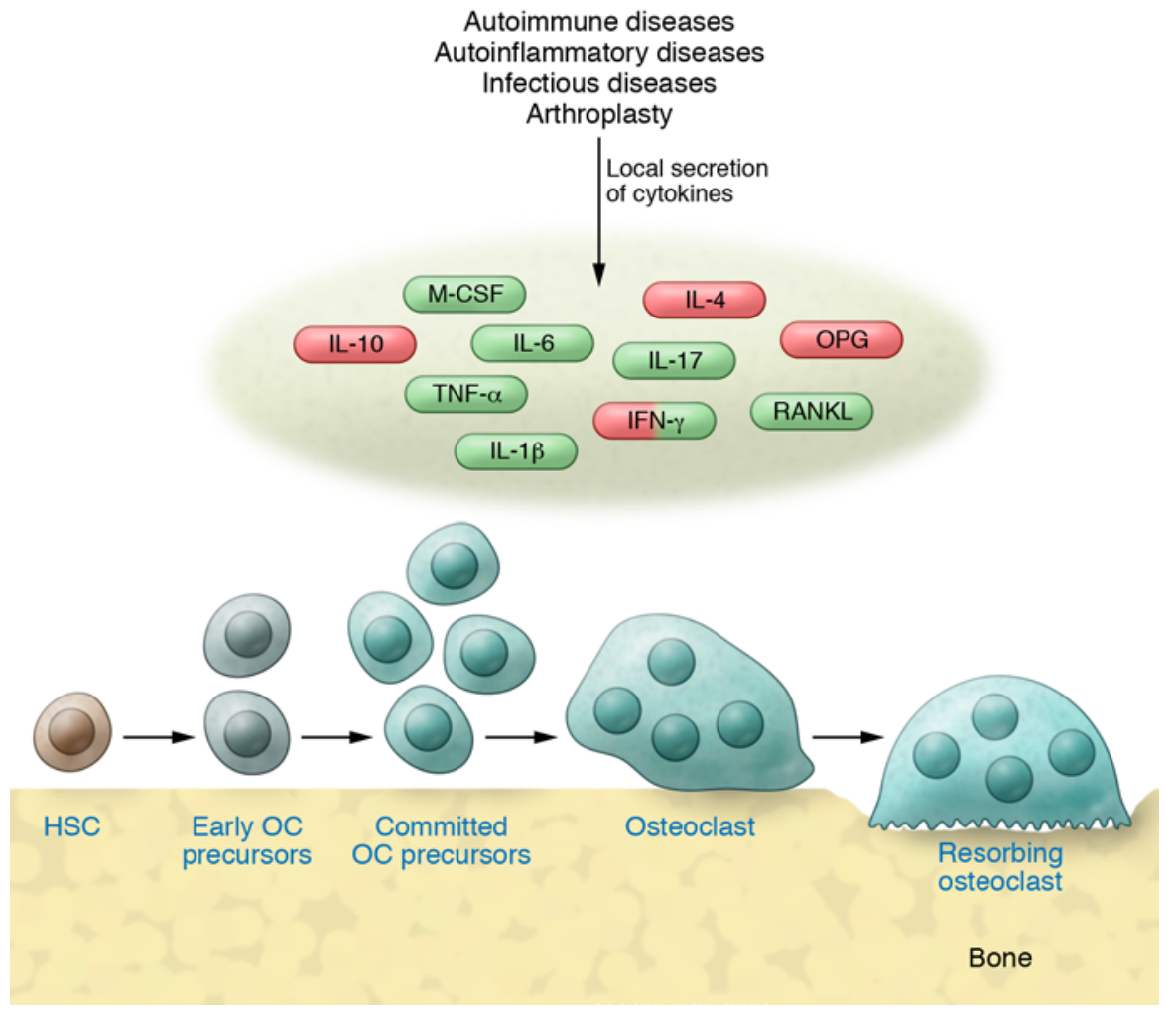

Figure 1. Cytokines are key regulators of inflammatory osteolysis. Despite differences in the pathogenesis of various inflammatory diseases, proximal regulators of osteoclastogenesis are the same, although the "cocktail" of these factors may differ. These factors may act at one or more aspects of the osteoclastogenic pathway from osteoclast generation to activation of resorption. While the homeostatic actions of pro-osteoclast factors (green) are balanced by those that are anti-osteoclast (red), pro-osteoclast factors dominate in inflammatory conditions, thereby increasing osteoclast number and enhancing the cell's capacity to resorb bone. Some factors, such as IFN- $\gamma$, have context-dependent effects on osteoclasts (see text). HSC, hematopoietic stem cell; OC, osteoclast. in states of inflammatory bone disease. Whereas RANKL increases osteoclast number by promoting precursor differentiation, M-CSF does so by enhancing proliferation of progenitors and restricting apoptosis. The capacity of the individual osteoclast to resorb bone, on the other hand, is largely a product of cytoskeletal organization. The resorptive machinery polarizes toward the cell-bone interface, enabling its transport into an isolated resorptive microenvironment in which degradation of the mineralized and organic components of the skeleton occurs sequentially (26). This process involves fusion of cytoplasmic vesicles containing matrix-degrading molecules to the bone-apposed plasma membrane. Fusion of these lysosome-derived vesicles to the plasma membrane generates the ruffled border, the unique resorptive organelle of the osteoclast, which transports mineral-mobilizing $\mathrm{HCl}$ and organic matrix-degrading cathepsin $\mathrm{K}$ into the resorptive space (27-31). Polarization of resorptive moleculecontaining vesicles is initiated by signals derived from mineralized matrix via cell surface integrins, particularly $\alpha v \beta 3$ (32). In addition to their role in osteoclast formation, both RANKL and M-CSF profoundly enhance bone resorption by the mature osteoclast via canonical organization of its cytoskeleton (33). Given the abundance of RANKL and M-CSF in states of inflammatory osteolysis, it is likely that the robust bone destruction reflects both increased numbers of osteoclasts and enhanced resorptive capacity of the mature cell. Thus, understanding the means by which inflammation destroys bone must be viewed in the context of interplay between cytokines that regulate these two critical osteoclastogenic factors.

\section{Cytokine-induced focal osteolysis in RA}

In many circumstances, osteolysis occurs adjacent to inflammation, such as in arthritic periarticular tissue. The secreted products of infiltrating immune cells perpetuate the inflammatory response that recruits osteoclasts, the direct mediators of the osteolytic component of the disease (Figure 1). Thus, anti-osteolytic strategies include inflammatory cytokine inhibition, such as TNF- $\alpha$ and IL-6 receptor blockade, both of which indirectly diminish osteoclastogenesis, as well as direct inhibition of osteoclast formation by agents such as denosumab, a humanized anti-RANKL antibody (34). The fact that NF- $\kappa$ B mediates both inflammation and osteoclast formation suggests its candidacy as a therapeutic target in inflammatory osteolysis (35-38). While an NF- $\mathrm{kB}$-focused strategy may be compromised by the broad biological necessity of the transcriptional complex, systemic administration of peptidesiRNA nanocomplexes targeting NF- $\kappa \mathrm{B}$ subunit p65 dramatically suppresses the inflammatory and bone-erosive components of experimental arthritis without apparent off-target effects (39).

A number of inflammatory cytokines may contribute to the periarticular bone loss of RA, but the most significant is TNF- $\alpha$. Macrophages and T cells express TNF- $\alpha$ in the arthritic synovial tissue as a membrane-residing protein that does not promote osteoclast formation until it is cleaved to its soluble form (40). Like RANKL, TNF- $\alpha$ exerts its biological effects by clustering and trimerizing three monomeric receptors (41). In fact, TNF- $\alpha$ activates two known receptor complexes, namely TNF receptor type 1 (TNFR1) and type 2 (TNFR2), and each prompts different intracellular events. TNFR1, which is principally stimulated by soluble TNF- $\alpha$, transmits proinflammatory signals and synergizes with RANK to promote osteoclastogenesis (42). Signals induced by TNFR2, which largely recognizes membrane-residing TNF- $\alpha$, are pro-immunogenic and anti-inflammatory (43). Thus, TNFR1 is responsible for the crippling effects of RA, PsA, and other forms of focal osteolysis, such as that complicating orthopedic implantation $(44,45)$. In fact, there is compelling evidence that complica- 
tions of anti-TNF- $\alpha$ therapy substantially reflect a failure to distinguish TNFR1 and TNFR2 $(46,47)$. Recently developed strategies, including manipulation of affinities for the two receptors to promote selective binding and thus inhibition of TNFR1 while sparing TNFR2, may attenuate the problematic properties of TNF- $\alpha$ while maintaining those that are salutary (48).

TNF- $\alpha$ potently stimulates osteoclast formation, but whether it does so independently of RANKL is controversial. Administration of TNF- $\alpha$ to RANKL-deficient mice fails to induce meaningful formation of the bone-resorptive cell (49), but TGF- $\beta$ may substitute for RANKL in certain circumstances (50). Challenging the concept that RANKL-independent osteoclast formation may participate in inflammatory bone loss is the finding that Rankl-knockout mice are protected from arthritic bone erosions (51). On the other hand, deletion of RBP-J, a transcription factor that inhibits osteoclast formation in the context of inflammation, enables RANKL-independent, TNF- $\alpha$-induced, but not physiological, osteoclastogenesis (52). Similarly, absence of TRAF3 or NF-кB2/ p100 alleviates inhibition of osteoclast formation in the context of TNF stimulation (53). Furthermore, combined TNF- $\alpha$ and IL-6 promote osteoclast formation and bone erosions in RANKdepleted myeloid precursors. Osteoclasts are also present, though diminished, in arthritic mice with inducible RANK deficiency (54). It therefore appears that in certain circumstances TNF- $\alpha$ may promote osteoclast formation in the absence of RANKL, but the biological significance of this event is yet to be defined. It is also clear that TNF- $\alpha$ and RANKL are synergistic, and the inflammatory cytokine needs only minimal amounts of RANKL to directly stimulate macrophages to differentiate into osteoclasts $(55,56)$. The osteoclast-inducing properties of relatively low quantities of TNF- $\alpha$ are largely the product of enhanced RANKL expression by mesenchymal cells, such as those residing in pannus, the inflamed and hypertrophied synovium of arthritic joints (57). As TNF- $\alpha$ abundance increases, its osteoclastogenic effects progressively reflect direct stimulation of myeloid precursors, while the contribution made by increasing RANKL diminishes $(55,57,58)$. Thus, osteolysis accompanying relatively modest elevations of ambient TNF- $\alpha$ depends upon responsive stromal cells. Alternatively, in states of severe periarticular inflammation, TNF- $\alpha$ may fully exert its bone-erosive effects by directly promoting differentiation of osteoclast precursors and their expression of RANK receptor independent of cytokine-responsive stromal cells and $\mathrm{T}$ lymphocytes (57). The capacity of TNF- $\alpha$ to prompt RANK expression and osteoclast formation is dependent upon its induction of M-CSF by stromal cells (59), which increases osteoclast precursor abundance (60). Importantly, antibody blockade of the M-CSF receptor C-FMS completely arrests TNF- $\alpha$-induced osteolysis, with minimal effects on macrophage number. C-FMS blockade also limited local and systemic resorption in two mouse models of inflammatory arthritis (61). Thus, M-CSF and its receptor are candidate therapeutic targets in inflammatory osteolysis.

Physiological bone remodeling is characterized by a "coupling" of osteoclast and osteoblast activity, and the same holds true in pathological conditions such as PsA (45). In contrast, the robust osteoclastogenesis of RA is accompanied by suppressed bone formation, and thus its erosive lesions exhibit limited osteoblast activity even in face of therapeutic intervention (62). TNF- $\alpha$ potently activates the canonical RelA pathway, which inhibits osteoblast differentiation, and therefore could contribute to the uncoupling of RA bone resorption from formation (63). However, this conclusion is controversial, as others report that NF- $\kappa \mathrm{B}$ positively affects osteogenesis (64). Given the central role of Wnt signaling in osteoblast differentiation, the failure of RA focal osteolysis to heal is perhaps more likely due to the osteogenic-suppressive properties of TNF- $\alpha$ mediated through its induction of dickkopf-1 (DKK-1), a potent inhibitor of Wnt activation (65-67). Interestingly, in contrast to TNF- $\alpha$ arrest, which suppresses osteoclastogenesis but does not increase bone formation, blockade of DKK-1 does both, thus repairing erosive lesions (66).

IL-1 $\beta$, which is abundant in RA pannus and other inflamed tissues, induces and partners with TNF- $\alpha$ to promote inflammatory osteolysis (58). In this circumstance, TNF- $\alpha$ enhances the synthesis of IL- $1 \beta$ by synovial fibroblasts (68) and macrophages. IL-1 $\beta$, in turn, stimulates expression of RANKL and RANK as well as its own receptor. In fact, IL- $1 \beta$ mediates approximately $50 \%$ of TNF- $\alpha$-induced osteoclastogenesis. The interdependency of TNF- $\alpha$, RANKL, and IL-1 $1 \beta$ lends credence to the concept that combined blockade more effectively prevents inflammatory bone loss than single cytokine inhibition (69).

\section{Autoantibody-induced focal osteolysis in RA}

While molecular effectors of innate immunity have been long recognized as mediators of bone loss, until recently little was known about the role of B cell-produced immunoglobulins as the key molecular effectors of adaptive immunity in skeletal degradation. Clinical observations suggested that rheumatoid factor, an immune complex induced by an IgM autoantibody against the Fc portion of IgG, and anti-citrullinated protein autoantibodies are potent risk factors for focal osteolysis in RA. Anti-citrullinated vimentin antibodies directly stimulate myeloid lineage cells to produce TNF- $\alpha$ and IL-8, which in turn induce osteoclastogenesis $(70,71)$. Furthermore, individuals with such antibodies but no signs of RA develop skeletal abnormalities, indicating a direct effect on bone (72). Immune complexes such as rheumatoid factors also stimulate osteoclast formation and function by crosslinking Fc receptors and activating $\operatorname{SYK}(73,74)$. Importantly, anti-citrullinated protein autoantibodies and rheumatoid factors additively trigger bone loss (75).

\section{IL-17 and focal osteolysis in PsA}

In contrast to RA, in which TNF- $\alpha$ predominates, PsA is characterized by robust activation of the IL-23/IL-17 axis (76). IL-17 is produced by Th17 and innate lymphoid (ILC3) cells exposed to IL-23. IL-17-expressing T cells infiltrate the skin and the joints of psoriatic patients and likely drive their clinical manifestations. Th17 cells synthesize IL-17 and express RANKL, both of which directly induce osteoclast differentiation (77, 78). Additionally, IL-17 potentiates RANKL's osteoclastogenic capacity by upregulating RANK on osteoclast precursor cells (79). IL-17 also indirectly promotes bone destruction by inducing synovial fibroblasts and macrophages, respectively, to express TNF- $\alpha$, IL-1, and IL-6 (80, 81). In fact, inducing osteolytic cytokines, especially TNF- $\alpha$, in these cells, may be the principal means by which IL-17 causes arthritic osteolysis. In contrast to IL-17, IL-23, 
the essential inducer of Th17 differentiation, does not directly promote osteoclast formation. The deleterious effects of IL-17 on bone also reflect suppressed osteogenesis via downregulation of Wnt and BMP pathways $(12,82)$.

Approximately $90 \%$ of PsA patients develop bone erosions that correlate with the magnitude of joint destruction, establishing a pathogenic role of the osteoclast. In contrast to RA, whose bone destructive complications are exclusively resorptive, PsA is characterized by not only robust bone resorption but also exuberant osteogenesis, particularly in regions of attachment of ligaments to bone (entheses), which can eventuate in ankyloses (83). While RA is exclusively characterized by synovial inflammation, patients with PsA also develop inflamed entheses that may reflect IL-23 and IL-17 activation. Although inflammation is a prerequisite for new bone formation at entheseal sites, IL-17 is unlikely the responsible factor, as it suppresses rather than promotes osteogenesis.

\section{Immunoregulatory mechanisms inhibiting focal arthritic osteolysis}

Macrophages are central to the pathogenesis of focal osteolysis, as they are a principal source of inflammatory cytokines and can differentiate into osteoclasts. In fact, the abundance of macrophages in pannus parallels disease severity (84). While the osteoclast is a macrophage lineage cell, its precise origin remains controversial and it is likely influenced by specific environmental circumstances. This is particularly true regarding the relationship of osteoclasts to classically activated, proinflammatory M1 and alternatively activated, immunoregulatory M2 macrophages. Assumption of the M2 phenotype typically requires IL-4 and IL-13, which inhibit osteoclast formation and induce myeloid progenitors to develop into non-bone-resorbing polykaryons (85). IL-4 and IL-13 are the products of Th2 lymphocytes and eosinophils, respectively. These cells suppress inflammatory arthritis and hence its osteolytic consequences (86). TNF- $\alpha$, which promotes osteoclast formation, blunts polarization to the M2 phenotype directly and by arresting production of IL-13 by eosinophils that are present in arthritic joints $(86,87)$. While these observations suggest that osteoclasts are not derived from alternatively activated M2 macrophages, inflammatory arthritis in mice recruits osteoclast precursors with features of both M1 and M2 cells (88). Hence, differentiation of a monocytic precursor into osteoclasts may essentially depend on the cytokine micro-milieu to which the cell is exposed, thus allowing a modicum of plasticity in monocyte differentiation.

In addition to stimulating resorption, immune cells may retard osteoclast formation and bone loss. For example, CD $4^{+}$ FoxP3 $^{+}$Tregs are potent inhibitors of osteoclast differentiation, exerting their effects by cell contact (89). The anti-resorptive capacity of Tregs reflects their anti-inflammatory properties. They also directly block osteoclast formation by liganding CD80/CD80 surface receptors with CTLA4, thereby inducing indoleamine 2,3-deoxygenase (IDO) (90). In inflammatory conditions, however, the immune-suppressive capacity of Tregs is compromised by proinflammatory cytokines, which promote targeted dephosphorylation of FoxP3 (91). A second population of Tregs that express CD8, known as Tcregs, is directly induced via interaction with osteoclasts (92). These Tcregs inhibit the resorptive activity of osteoclasts, rather than inhibiting their differentiation in vitro, and limit bone loss in mice following RANKL injection or ovariectomy (92-94). Whether the osteoclast-suppressive properties of Tregs or Tcregs are compromised in inflamed joints is unknown.

Understanding the role of Th1 cells in the skeleton has been more complex than exploring Tregs. Activated Th1 cells were originally considered pro-osteoclastogenic, as they express RANKL (95). Th1 cells, however, actually suppress osteoclast formation in vitro, postulated to be via co-production of IFN- $\gamma$, challenging their role in RA-associated focal osteolysis $(18,78)$. Surprisingly, however, human $\mathrm{CD} 4^{+} \mathrm{IFN}-\gamma^{+} \mathrm{T}$ but not $\mathrm{CD} 4^{+} \mathrm{IFN}-\gamma^{-} \mathrm{T}$ cells express RANKL and thus promote osteoclastogenesis (96). Importantly, $\mathrm{CD} 4^{+} \mathrm{IFN}-\gamma^{+} \mathrm{T}$ cells are selectively increased in the circulation of RA patients and IFN- $\gamma$ stimulates osteoclast formation and bone loss in vivo $(96,97)$. Thus, Th1-produced IFN- $\gamma$ appears to directly inhibit and indirectly stimulate osteoclast formation, with the latter predominating in vivo.

\section{Skeletal changes associated with excessive inflammasome activation}

Inflammasomes are intracellular protein complexes expressed mainly by myeloid cells, including osteoclasts $(98,99)$, but also develop in osteoblasts and chondrocytes $(98,100,101)$. They protect against infections upon recognition of microbial structures known as pathogen-associated molecular patterns (PAMPs) (102). Inflammasomes also restore tissue integrity after injury by sensing danger-associated molecular patterns (DAMPs) from damaged cells (103-105). They function primarily by converting pro-IL-1 $\beta$ and pro-IL-18 to their biologically active forms (103).

Inflammasomes are assembled by nucleotide-binding oligomerization domain, leucine-rich repeat-containing proteins (NLRP1, NLRP3, NLRC4, NLRP6, and NLRP12), absent in melanoma 2-like (AIM 2-like) receptors (known as ALRs), or pyrin (ref. 103 and Figure 2). These proteins act as receptors for PAMP- and DAMP-associated molecular patterns. Ligand recognition enables the recruitment and oligomerization of apoptosis-associated speck-like protein containing a caspase activation recruitment domain (CARD). Complex assembly activates caspase 1, which proteolytically processes pro-IL-1 $\beta$ and pro-IL-18. The NLRP3 inflammasome signaling cascade cleaves poly(ADP-ribose) polymerase 1 (PARP1) (106-108).

Owing to its robust activation by monosodium urate crystals, the NLRP3 inflammasome plays a key role in gout (109). The NLRP3 inflammasome is also activated in RA synovium, consistent with increased IL-1 $\beta$ secretion $(110,111)$. TNF- $\alpha$ stimulates IL-1 $\beta$ expression in vitro, suggesting the latter cytokine may drive pro-IL- $1 \beta$ transcription in RA. Although TNF- $\alpha$ and IL- $1 \beta$ regulate each other's expression and osteoclastogenic properties (58), the superior efficacy of TNF- $\alpha$ inhibitors in RA relative to those that block IL- 1 is consistent with the apical role of TNF- $\alpha$ in generating focal osteolysis in this disease.

As stated above, inflammasomes also promote cleavage of PARP1 (106-108). While it has yet to be studied in the context of RA, PARP1 proteolysis occurs during osteoclastogenesis (98, $99,112,113)$. A proteolytically stable PARP1 mutant antagonizes osteoclastogenesis, whereas PARP1 deficiency enhances this process $(107,114)$, indicating that PARP1 negatively regulates osteoclast differentiation. 


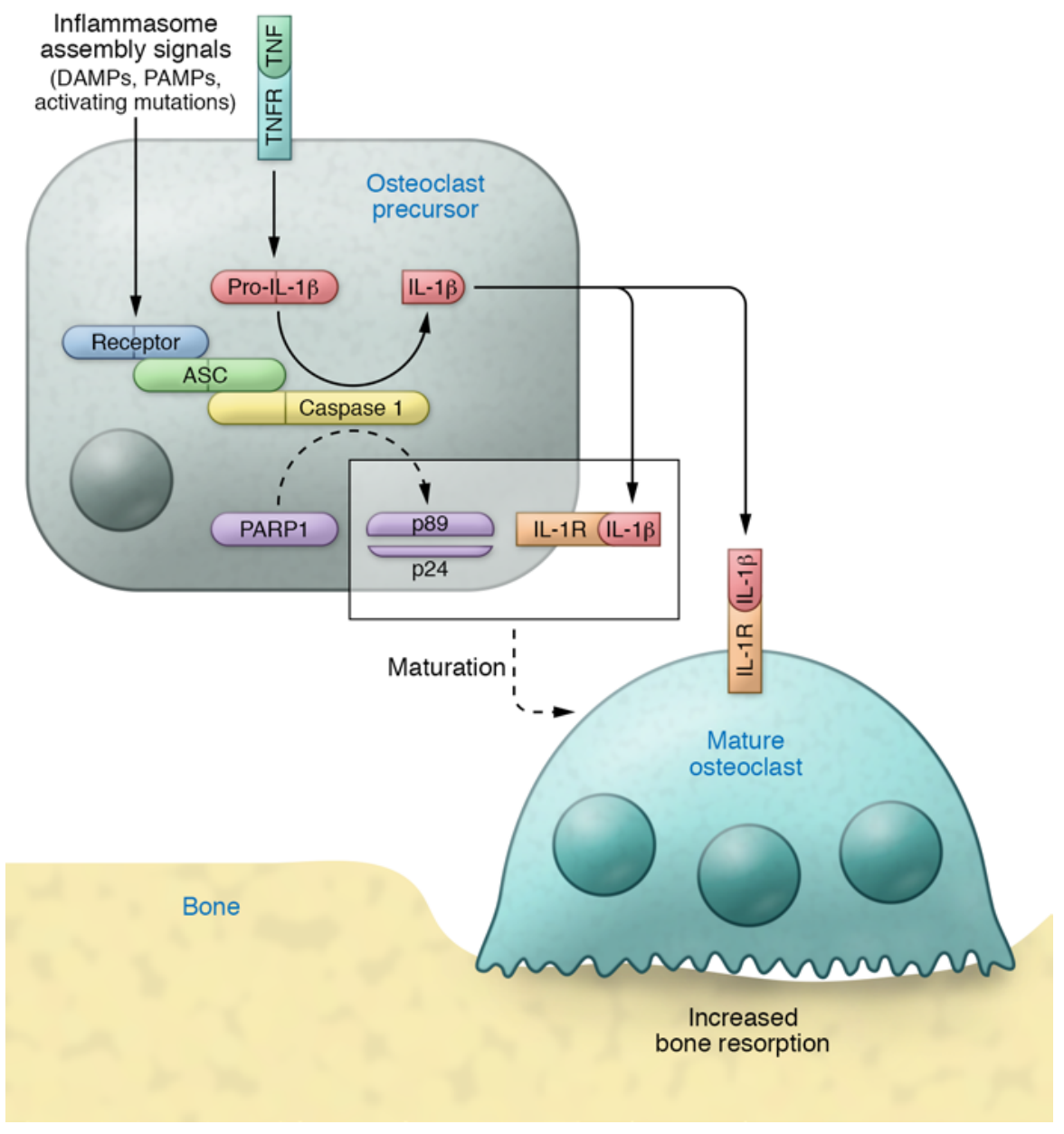

Figure 2. The inflammasomes in osteolysis. Cytokines such as TNF induce the expression of pro-IL-1 $1 \beta$, which lacks the signal peptide for secretion. Recognition of damage- or pathogenassociated molecular patterns (DAMPs or PAMPs) by the receptor/sensor component of the inflammasome (e.g., NLRP3, NLRC4), or activating mutations of some of these receptors leads to the assembly of the inflammasome, a protein complex containing the receptor, apoptosis-associated speck-like protein containing a CARD (ASC) and caspase 1. Once assembled, this active complex cleaves pro-IL-1 $\beta$ into active IL-1 $\beta$ and triggers cascades that lead to PARP1 cleavage into $p 89$ and p24 fragments. In precursors sensing DAMPs or PAMPs, cleaved PARP1 and autocrine effects of IL-1 $\beta$, acting through $\mathrm{IL}-1 \mathrm{R}$, promote maturation of osteoclasts into bone-resorbing cells. Secreted IL-1 $\beta$ can also act in a paracrine manner to increase bone resorption by nearby osteoclasts. Dashed arrows indicate multiple steps.
Inflammasome mutations may prompt stimulus-independent activation and are the cause of cryopyrin-associated periodic syndromes (CAPS). Neonatal-onset multisystem inflammatory disease (NOMID), the most severe CAPS, is attended by bone loss and skeletal deformation (101, 115-118). IL-1-blocking agents have limited efficacy against NOMID skeletal lesions, while other symptoms related to systemic inflammation are rapidly resolved (119-122). While the human disease is phenocopied in mouse models with global NOMID mutation $(98,123)$, mice bearing the mutation only in osteoclasts lack systemic inflammation but have severe osteoporosis (99), indicating a cell-autonomous role in the bone-resorptive cell.

In humans, gain-of-function mutations in NLRC4 cause a disorder reminiscent of macrophage activation syndrome (MAS) (124-127), a life-threatening complication of systemic juvenile idiopathic arthritis (JIA). JIA responds to IL-1 blockers $(128,129)$, indicating the inflammasome-activated cytokine participates in this osteolytic disorder. Consistent with the human phenotype, transgenic mice expressing constitutively active NLRC4 develop inflammatory arthritis (130). Similarly, activating mutations of $M E F V$, encoding pyrin, cause familial Mediterranean fever (FMF), which is characterized by excessive IL-1 $\beta$ that drives autoinflammation associated with arthritis and bone loss $(131,132)$. The efficacy of IL-1 blockers underscores the pathogenic action of this cytokine in FMF (133).
Additionally, mice harboring mutant MEFV establish that the pyrin inflammasome is proinflammatory and causes massive cartilage and bone erosion (134).

Chronic recurrent multifocal osteomyelitis (CRMO) is an autoinflammatory osteolytic disorder. Anti-inflammatory cytokines (e.g., IL-10) are diminished, whereas their proinflammatory counterparts (e.g., IL-1 $\beta$, IL-6, and TNF- $\alpha$ ) are increased. This imbalance presumably reflects NLRP3 inflammasome hyperactivation and causes exaggerated osteoclastogenesis (135). Immunohistochemical staining of bone of CRMO patients shows that the NLRP3 inflammasome is increased in osteoclasts (136). Supporting the role of cytokines in bone loss during CRMO, TNF- $\alpha$ or IL-1 blockers are efficacious (135). Mice harboring a spontaneous missense mutation in the proline-serine-threonine phosphatase-interacting protein 2 (Pstpip2) gene, which abolishes protein expression, develop a phenotype reminiscent of CRMO, with enhanced osteoclastogenesis and bone resorption (137). These mutant mice overproduce IL- $1 \beta$ due to combined and redundant actions of the NLRP3 inflammasome and caspase 8 (138-140), suggesting that inflammasome-independent IL-1 $\beta$ release may occur in some situations.

\section{Pathogenesis of periprosthetic osteolysis}

Periprosthetic osteolysis is the most significant long-term complication of total hip replacement. Prosthetic-wear particles activate innate immune responses, causing excessive bone resorption and, 
ultimately, implant failure $(141,142)$. The prevalence of myeloid cell responses indicates that the NLRP3 inflammasome likely participates in prosthetic loosening, implicating crystalline particles in the pathogenesis of NLRP3-mediated diseases. Furthermore, calvarial bone resorption that is induced by polymethylmethacrylate (PMMA) particles is reduced in the absence of NLRP3 (143). The size and shape of metal alloys affect the amplitude of the inflammasome response (144). Plastic components of the prostheses also activate the inflammasome. Phagocytosis-enhanced production of reactive oxygen species and rupture of phagosomes, which release cathepsins in the cytoplasm, are the presumed mechanisms of NLRP3 inflammasome activation by particles. On the other hand, prosthetic particles generate priming signals through TLRs that induce expression of pro-IL-1 $\beta$ and NLRP3 $(145,146)$. The NLRP3 inflammasome, however, appears to supersede TLR4 signaling in prosthetic-wear particle-induced osteolysis (147). On the other hand, the non-NLR inflammasome AIM2 and not NLRP3 may mediate the acute phase of PMMA-induced foreign body responses (148).

\section{Infection-associated osteolysis}

Immune activation during infection causes profound local bone loss. Although the term may refer to any instance of bone inflammation, osteomyelitis $(\mathrm{OM})$ is primarily used to describe the infection-induced form of disease whose progression is the result of interplay among pathogens, the cellular and matrix constituents of bone, and the immune system. Bacteria may cause bone necrosis through direct killing of osteoblasts, but the inflammatory response is likely the major event by which infection induces osteoclastogenesis and bone degradation. The most frequently identified microorganism in OM is Staphylococcus aureus, which is seeded into bone through both hematogenous and direct (e.g., trauma, implant) routes in children and adults (149).

Bacterial products of Staphylococcus aureus, which grows primarily in the extracellular bone microenvironment and forms biofilms, induce an inflammatory response. Factors released by cells adjacent to bacteria include TNF- $\alpha$, IL-1 $\beta$, IL-6, IFN- $\gamma$, and IL-12 as well as the chemokines CCL3 (also known as MIP1 $\alpha$ ), CXCL1, CXCL2 (also known as MIP2 $\alpha$ ), and CXCL8 (150-154). Further linking mechanisms of bone loss in infectious and non-infectious inflammatory states, the NLRP3 inflammasome is implicated in the response of innate immune cells to Staphylococcus aureus infection. Hemolysins, bacterial lipoproteins, and Panton-Valentine leukocidin from Staphylococcus aureus are all activators of NLRP3 capable of inducing IL-1 $\beta$ release (155-157). In addition to the caspase 1 -mediated IL-1 $\beta$ processing event, NLRP3 activation induces expression of a variety of cytokines in an NF-кB-dependent, caspase 1-independent fashion (158). As discussed above, although individual inflammasome factors may inhibit osteoclast formation or function, combined release is highly osteolytic $(151,159,160)$.

In addition to mediating osteolysis via activation of immune cells, Staphylococcus aureus directly affects osteoblasts. Staphylococcal protein A binds to and activates TNFR1 on osteoblasts, thereby stimulating NF- $\mathrm{BB}$ and promoting IL-6 secretion (161). The cell wall component peptidoglycan stimulates TLR2 in a NOD2-dependent manner, thereby inducing RANKL expression by osteoblasts. Concordant OPG remains unchanged $(159,162$, 163) or decreases (164), contributing to osteoclast recruitment and osteolysis. Bone loss likely also occurs through reduced osteoblast viability as well as reduced activity induced by substances released from staphylococcal biofilms $(163,164)$.

Alveolar bone loss due to periodontitis is another frequent form of infection-mediated inflammatory osteolysis. In this context, the most common pathogen is Porphyromonas gingivalis, although the human disease is likely polymicrobial, as the oral cavity is not a sterile site (165). Alveolar bone loss elicited by Porphyromonas gingivalis shares many features of lysis attending OM. Cytokine release (166) as well as induction of RANKL downstream of TLR2 and NOD2 are the prominent pathways leading to osteoclast activation in periodontitis $(167,168)$. IL-17 is also markedly increased in periodontitis and appears to be an important factor in both inflammation and osteolysis of the periodontal tissue (169). Porphyromonas gingivalis also releases cysteine proteases called gingipains, which do not directly induce osteoclastogenesis (170) but may act via differential degradation of osteoclast-modulatory cytokines, including OPG (171).

\section{Therapeutic perspective}

In the not-too-distant past, many patients with RA or PsA were incapacitated because of focal osteolysis, which destroyed periarticular bone. Insights gained into the pathogenesis of inflammatory osteolysis, and in particular the interplay of the immune and skeletal systems, has led to substantial therapeutic progress. RANKL inhibition by denosumab, for example, arrests progression of arthritic osteolysis, supporting the concept that stimulated osteoclastogenesis is the essential event in inflammatory bone loss (172). However, RANKL inhibition, per se, has no intrinsic anti-inflammatory properties and therefore must be accompanied by anti-inflammatory agents in these disorders (172). All current cytokine inhibitors approved for the treatment of inflammatory diseases, which include compounds specifically targeting IL-1, IL-6R, IL-17, IL-12/23, and in particular TNF- $\alpha$, limit osteolysis (173-175). The efficacy of TNF- $\alpha$ inhibitors appears to reflect combined anti-inflammatory properties and direct suppression of bone-resorbing osteoclasts. IL-6R inhibitors, which are used exclusively to treat RA, and IL-12/23 and IL-17 blocking agents, predominantly employed in psoriatic arthritis, exert similar bone-protective effects. The impressive skeletal-sparing properties of IL-1 blockers are surprising, as these drugs minimally diminish the articular inflammation of RA, supporting the concept that the cytokine's primary effect, in the disease, is direct osteoclast recruitment and activation (176). Clinically, IL-1 inhibitors may have their primary bone-protective role in crystal arthropathies such as gout, where IL-1 $\beta$ plays a dominant role as an inflammatory cytokine (177). A small molecule inhibitor of the NLRP3 inflammasome has shown efficacy in rodent disease models (178), thus providing proof of concept that pharmacologic inhibition of this inflammasome is a viable therapeutic strategy. However, there is no report on NLRP3 inhibitors in clinical development. Drugs interfering with adaptive immune response, particularly $\mathrm{T}$ cell activation, also regulate bone resorption. CTLA4, for instance, which retards $\mathrm{T}$ cell activation and is effective in RA, binds osteoclast precursors and arrests their differentiation (179). The anti-osteoclastogenic properties of Tregs are mediated by CTLA4, which these cells constitutively express (179). 
Since infection-induced osteolysis is primarily the result of the host response rather than the direct action of pathogens, blockade of cytokines and/or RANKL could be a useful adjunct to debridement and antibiotic therapy. RANKL blockade has been successful in animal models of periodontitis (180-182). Patients treated with anti-TNF- $\alpha$ therapy for other disorders have also shown some improvement in alveolar bone loss (183).

In summary, while the clinical consequences of skeletal inflammation have long been appreciated, recent discoveries of immune pathways controlling bone homeostasis have added greatly to our understanding as to how these pathological events occur. Inflammatory cytokines, autoantibodies, and DAMPs/ PAMPs induce osteoclast differentiation and osteolysis in autoinflammatory, autoimmune, and infectious diseases. These discoveries prompted therapeutic interventions, such as cytokine blockers, which selectively disrupt the detrimental skeletal effects of chronic immune activation and inflammation, thereby limiting their associated bone loss. Further examination of immune pathways will likely lead to additional approaches to the treatment of inflammatory osteolysis.

\section{Acknowledgments}

GM is supported by NIH/NIAMS grants AR064755 and AR068972, and is Co-Founder of Confluence Life Sciences Inc. DVN is supported by NIH/NIAMS AR052705 and AR070030. GS is supported by DFG projects SPP1468 and CRC1181. SLT is supported by NIH/NIAMS AR046523 and Shriners Hospitals for Children grant 85400-STL.

Address correspondence to: Steven L. Teitelbaum, Washington University School of Medicine, Department of Pathology and Immunology, Campus Box 8118, 660 South Euclid Avenue, St. Louis, Missouri 63110, USA. Phone:314.454.8463; E-mail: teitelbs@wustl.edu.
1. van Staa TP, Geusens P, Bijlsma JW, Leufkens HG, Cooper C. Clinical assessment of the long-term risk of fracture in patients with rheumatoid arthritis. Arthritis Rheum. 2006;54(10):3104-3112.

2. Kocijan R, et al. Quantitative and qualitative changes of bone in psoriasis and psoriatic arthritis patients. J Bone Miner Res. 2015;30(10):1775-1783.

3. Haschka J, et al. High-resolution quantitative computed tomography demonstrates structural defects in cortical and trabecular bone in IBD patients. J Crohns Colitis. 2016;10(5):532-540.

4. Schett G, et al. High-sensitivity C-reactive protein and risk of nontraumatic fractures in the Bruneck study. Arch Intern Med. 2006;166(22):2495-2501.

5. Pasco JA, et al. High-sensitivity C-reactive protein and fracture risk in elderly women. JAMA. 2006;296(11):1353-1355.

6. Rubbert-Roth A, Finckh A. Treatment options in patients with rheumatoid arthritis failing initial TNF inhibitor therapy: a critical review. Arthritis Res Ther. 2009;11 Suppl 1:S1.

7. Horton JE, Raisz LG, Simmons HA, Oppenheim JJ, Mergenhagen SE. Bone resorbing activity in supernatant fluid from cultured human peripheral blood leukocytes. Science. 1972;177(4051):793-795.

8. Dewhirst FE, Stashenko PP, Mole JE, Tsurumachi T. Purification and partial sequence of human osteoclast-activating factor: identity with interleukin 1 beta. J Immunol. 1985;135(4):2562-2568 .

9. Lacey DL, et al. Osteoprotegerin ligand is a cytokine that regulates osteoclast differentiation and activation. Cell. 1998;93(2):165-176.

10. Pacifici R. Role of T cells in ovariectomy induced bone loss - revisited. J Bone Min Res. 2012;27(2):231-239.

11. Redlich K, Smolen JS. Inflammatory bone loss: pathogenesis and therapeutic intervention. Nat Rev Drug Discov. 2012;11(3):234-250.

12. Gravallese EM, Harada Y, Wang JT, Gorn AH, Thornhill TS, Goldring SR. Identification of cell types responsible for bone resorption in rheumatoid arthritis and juvenile rheumatoid arthritis. Am J Pathol. 1998;152(4):943-951.

13. Buchwald ZS, et al. A bone anabolic effect of RANKL in a murine model of osteoporosis mediated through $\mathrm{FoxP}^{+} \mathrm{CD} 8 \mathrm{~T}$ cells. J Bone Miner Res. 2015;30(8):1508-1522.
14. Lam J, Nelson CA, Ross FP, Teitelbaum SL, Fremont DH. Crystal structure of the TRANCE/ RANKL cytokine reveals determinants of receptor-ligand specificity. J Clin Invest. 2001;108(7):971-979.

15. Nelson CA, Warren JT, Wang MW, Teitelbaum SL, Fremont DH. RANKL employs distinct binding modes to engage RANK and the osteoprotegerin decoy receptor. Structure. 2012;20(11):1971-1982.

16. Kobayashi N, et al. Segregation of TRAF6-mediated signaling pathways clarifies its role in osteoclastogenesis. EMBO J. 2001;20(6):1271-1280.

17. Lin J, Lee D, Choi Y, Lee SY. The scaffold protein RACK1 mediates the RANKL-dependent activation of p38 MAPK in osteoclast precursors. Sci Signal. 2015;8(379):ra54.

18. Takayanagi $\mathrm{H}$, et al. T-cell-mediated regulation of osteoclastogenesis by signalling cross-talk between RANKL and IFN- $\gamma$. Nature. 2000;408(6812):600-605.

19. Asagiri M, et al. Autoamplification of NFATc1 expression determines its essential role in bone homeostasis. JExp Med. 2005;202(9):1261-1269.

20. Novack DV. Role of NF-кB in the skeleton. Cell Res. 2011;21(1):169-182.

21. Min H, et al. Osteoprotegerin reverses osteoporosis by inhibiting endosteal osteoclasts and prevents vascular calcification by blocking a process resembling osteoclastogenesis. JExp Med. 2000;192(4):463-474.

22. Bucay N, et al. osteoprotegerin-deficient mice develop early onset osteoporosis and arterial calcification. Genes Dev. 1998;12(9):1260-1268.

23. Mizuno A, et al. Severe osteoporosis in mice lacking osteoclastogenesis inhibitory factor/ osteoprotegerin. Biochem Biophys Res Commun. 1998;247(3):610-615.

24. Whyte MP, et al. Osteoprotegerin deficiency and juvenile Paget's disease. $N$ Engl J Med. 2002;347(3):175-184.

25. Ross FP, Teitelbaum SL. alphavbeta3 and macrophage colony-stimulating factor: partners in osteoclast biology. Immunol Rev. 2005;208:88-105.

26. Teitelbaum SL, Zou W. The osteoclast cytoskeleton: how does it work? IBMS BoneKEy. 2011;8:74-83.

27. DeSelm CJ, et al. Autophagy proteins regulate the secretory component of osteoclastic bone resorption. Dev Cell. 2011;21(5):966-974.

28. Zhao H, Ito Y, Chappel J, Andrews NW, Teitelbaum SL, Ross FP. Synaptotagmin VII regulates bone remodeling by modulating osteoclast and osteoblast secretion. Dev Cell.2008;14(6):914-925.

29. Blair HC, Teitelbaum SL, Ghiselli R, Gluck S. Osteoclastic bone resorption by a polarized vacuolar proton pump. Science. 1989;245(4920):855-857.

30. Schmidt S, et al. Kindlin-3-mediated signaling from multiple integrin classes is required for osteoclast-mediated bone resorption. J Cell Biol. 2011;192(5):883-897.

31. Baron R, Neff L, Louvard D, Courtoy PJ. Cellmediated extracellular acidification and bone resorption: evidence for a low $\mathrm{pH}$ in resorbing lacunae and localization of a 100-kD lysosomal membrane protein at the osteoclast ruffled border. JCell Biol. 1985;101(6):2210-2222.

32. Zou W, Teitelbaum SL. Absence of Dap12 and the av 33 integrin causes severe osteopetrosis. JCell Biol. 2015;208(1):125-136.

33. Faccio R, Novack DV, Zallone A, Ross FP, Teitelbaum SL. Dynamic changes in the osteoclast cytoskeleton in response to growth factors and cell attachment are controlled by beta 3 integrin. JCell Biol. 2003;162(3):499-509.

34. Takeuchi T, et al. Effect of denosumab on Japanese patients with rheumatoid arthritis: a dose-response study of AMG 162 (Denosumab) in patients with rheumatoId arthritis on methotrexate to Validate inhibitory effect on bone erosion (DRIVE)-a 12-month, multicentre, randomised, double-blind, placebo-controlled, phase II clinical trial. Ann Rheum Dis. 2016;75(6):983-990.

35. Clohisy JC, et al. Direct inhibition of NF- $\mathrm{kB}$ blocks bone erosion associated with inflammatory arthritis. J Immunol. 2003;171(10):5547-5553.

36. Aya K, Alhawagri M, Hagen-Stapleton A, Kitaura H, Kanagawa O, Novack DV. NIK controls lymphocyte and osteoclast activities in inflammatory arthritis. JClin Invest. 2005;115(7):1848-1854.

37. Ruocco MG, et al. IкB kinase (IKK) $\beta$, but not $\mathrm{IKK} \alpha$, is a critical mediator of osteoclast survival and is required for inflammation-induced bone loss. J Exp Med. 2005;201(10):1677-1687. 
38. Jimi $\mathrm{E}$, et al. Selective inhibition of NF- $\mathrm{\kappa B}$ blocks osteoclastogenesis and prevents inflammatory bone destruction in vivo. Nat Med. 2004;10(6):617-624.

39. Zhou HF, et al. Peptide-siRNA nanocomplexes targeting NF- $\kappa B$ subunit $\mathrm{p} 65$ suppress nascent experimental arthritis. JClin Invest. 2014;124(10):4363-4374.

40. Abu-Amer Y, Erdmann J, Alexopoulou L, Kollias G, Ross FP, Teitelbaum SL. Tumor necrosis factor receptors types 1 and 2 differentially regulate osteoclastogenesis. J Biol Chem. 2000;275(35):27307-27310.

41. Mukai Y, et al. Solution of the structure of the TNF-TNFR2 complex. Sci Signal. 2010;3(148):ra83.

42. Van Hauwermeiren F, Vandenbroucke RE, Libert C. Treatment of TNF mediated diseases by selective inhibition of soluble TNF or TNFR1. Cytokine Growth Factor Rev. 2011;22(5-6):311-319.

43. Faustman D, Davis M. TNF receptor 2 pathway: drug target for autoimmune diseases. Nat Rev Drug Discov. 2010;9(6):482-493.

44. Merkel KD, Erdmann JM, McHugh KP, Abu-Amer Y, Ross FP, Teitelbaum SL. Tumor necrosis factor- $\alpha$ mediates orthopedic implant osteolysis. Am J Pathol. 1999;154(1):203-210.

45. Mensah KA, Schwarz EM, Ritchlin CT. Altered bone remodeling in psoriatic arthritis. Curr Rheumatol Rep. 2008;10(4):311-317.

46. Blüml S, Scheinecker C, Smolen JS, Redlich K. Targeting TNF receptors in rheumatoid arthritis. Int Immunol. 2012;24(5):275-281.

47. Kollias G, Kontoyiannis D. Role of TNF/TNFR in autoimmunity: specific TNF receptor blockade may be advantageous to anti-TNF treatments. Cytokine Growth Factor Rev. 2002;13(4-5):315-321.

48. Warren JT, Nelson CA, Decker CE, Zou W, Fremont DH, Teitelbaum SL. Manipulation of receptor oligomerization as a strategy to inhibit signaling by TNF superfamily members. Sci Signal. 2014;7(339):ra80.

49. Li J, et al. RANK is the intrinsic hematopoietic cell surface receptor that controls osteoclastogenesis and regulation of bone mass and calcium metabolism. Proc Natl Acad Sci U S A. 2000;97(4):1566-1571.

50. Kim N, et al. Osteoclast differentiation independent of the TRANCE-RANK-TRAF6 axis. JExp Med. 2005;202(5):589-595.

51. Pettit A, et al. TRANCE/RANKL knockout mice are protected from bone erosion ina serum transfer model of arthritis. Am J Pathol. 2001;159(5):1689-1699.

52. Zhao B, Grimes SN, Li S, Hu X, Ivashkiv LB. TNF-induced osteoclastogenesis and inflammatory bone resorption are inhibited by transcription factor RBP-J.JExp Med. 2012;209(2):319-334.

53. Yao Z, Xing L, Boyce BF. NF-кB p100 limits TNF-induced bone resorption in mice by a TRAF3-dependent mechanism. J Clin Invest. 2009;119(10):3024-3034.

54. O'Brien W, et al. RANK-independent osteoclast formation and bone erosion in inflammatory arthritis. Arthritis Rheumatol. 2016;68(12):2889-2900.

55. Lam J, Takeshita S, Barker JE, Kanagawa O, Ross FP, Teitelbaum SL. TNF- $\alpha$ induces osteoclastogenesis by direct stimulation of macrophages exposed to permissive levels of RANK ligand. J Clin Invest. 2000;106(12):1481-1488.

56. Zhang YH, Heulsmann A, Tondravi MM, Mukherjee A, Abu-Amer Y. Tumor necrosis factor- $\alpha$ (TNF) stimulates RANKL-induced osteoclastogenesis via coupling of TNF type 1 receptor and RANK signaling pathways. J Biol Chem. 2001;276(1):563-568.

57. Kitaura H, et al. Marrow stromal cells and osteoclast precursors differentially contribute to TNF$\alpha$-induced osteoclastogenesis in vivo. JImmunol. 2004;173(8):4838-4846.

58. Wei S, Kitaura H, Zhou P, Ross FP, Teitelbaum SL. IL-1 mediates TNF-induced osteoclastogenesis. JClin Invest. 2005;115(2):282-290.

59. Ito H, Yamada H, Shibata TN, Mitomi H, Nomoto S, Ozaki S. Dual role of interleukin-17 in pannus growth and osteoclastogenesis in rheumatoid arthritis. Arthritis Res Ther. 2011;13(1):R14.

60. Kitaura H, Zhou P, Kim HJ, Novack DV, Ross FP, Teitelbaum SL. M-CSF mediates TNF-induced inflammatory osteolysis. JClin Invest. 2005;115(12):3418-3427.

61. Toh ML, et al. Bone- and cartilage-protective effects of a monoclonal antibody against colony-stimulating factor 1 receptor in experimental arthritis. Arthritis Rheumatol. 2014;66(11):2989-3000.

62. Finzel S, Rech J, Schmidt S, Engelke K, Englbrecht M, Schett G. Interleukin-6 receptor blockade induces limited repair of bone erosions in rheumatoid arthritis: a micro CT study. Ann Rheum Dis. 2013;72(3):396-400.

63. Chang J, et al. Inhibition of osteoblastic bone formation by nuclear factor-kappaB. Nat Med. 2009;15(6):682-689.

64. Osta B, Benedetti G, Miossec P. Classical and paradoxical effects of TNF- $\alpha$ on bone homeostasis. Front Immunol. 2014;5:48.

65. Wang SY, et al. Circulating Dickkopf-1 is correlated with bone erosion and inflammation in rheumatoid arthritis. J Rheumatol. 2011;38(5):821-827.

66. Diarra D, et al. Dickkopf-1 is a master regulator of joint remodeling. Nat Med.2007;13(2):156-163.

67. Walsh NC, et al. Osteoblast function is compromised at sites of focal bone erosion in inflammatory arthritis. JBone Miner Res. 2009;24(9):1572-1585.

68. Tian J, Chen JW, Gao JS, Li L, Xie X. Resveratrol inhibits TNF- $\alpha$-induced IL-1 $\beta$, MMP-3 production in human rheumatoid arthritis fibroblast-like synoviocytes via modulation of PI3kinase/Akt pathway. Rheumatol Int. 2013;33(7):1829-1835.

69. Zwerina J, et al. Single and combined inhibition of tumor necrosis factor, interleukin-1, and RANKL pathways in tumor necrosis factorinduced arthritis: effects on synovial inflammation, bone erosion, and cartilage destruction. Arthritis Rheum. 2004;50(1):277-290.

70. Harre U, et al. Induction of osteoclastogenesis and bone loss by human autoantibodies against citrullinated vimentin. J Clin Invest. 2012;122(5):1791-1802.

71. Krishnamurthy A, et al. Identification of a novel chemokine-dependent molecular mechanism underlying rheumatoid arthritis-associated autoantibody-mediated bone loss. Ann Rheum Dis. 2016;75(4):721-729.

72. Kleyer A, et al. Bone loss before the clinical onset of rheumatoid arthritis in subjects with antici- trullinated protein antibodies. Ann Rheum Dis. 2014;73(5):854-860.

73. Harre U, et al. Glycosylation of immunoglobulin $G$ determines osteoclast differentiation and bone loss. Nat Commun. 2015;6:6651.

74. Negishi-Koga T, et al. Immune complexes regulate bone metabolism through $\mathrm{FcR} \gamma$ signalling. Nat Commun. 2015;6:6637.

75. Hecht C, et al. Additive effect of anti-citrullinated protein antibodies and rheumatoid factor on bone erosions in patients with RA. Ann Rheum Dis. 2015;74(12):2151-2156.

76. Schett G, Elewaut D, McInnes IB, Dayer JM, Neurath MF. How cytokine networks fuel inflammation: toward a cytokine-based disease taxonomy. Nat Med. 2013;19(7):822-824.

77. Kotake S, et al. IL-17 in synovial fluids from patients with rheumatoid arthritis is a potent stimulator of osteoclastogenesis. JClin Invest. 1999;103(9):1345-1352.

78. Sato K, et al. Th17 functions as an osteoclastogenic helper $\mathrm{T}$ cell subset that links $\mathrm{T}$ cell activation and bone destruction. J Exp Med. 2006;203(12):2673-2682.

79. Adamopoulos IE, et al. Interleukin-17A upregulates receptor activator of NF- $\mathrm{kB}$ on osteoclast precursors. Arthritis Res Ther. 2010;12(1):R29.

80. Katz Y, Nadiv O, Beer Y. Interleukin-17 enhances tumor necrosis factor $\alpha$-induced synthesis of interleukins 1,6, and 8 in skin and synovial fibroblasts: a possible role as a "fine-tuning cytokine" in inflammation processes. Arthritis and Rheumatism. 2001;44(9):2176-2184.

81. Jovanovic DV, et al. IL-17 stimulates the production and expression of proinflammatory cytokines, IL- $\beta$ and TNF- $\alpha$, by human macrophages. J Immunol. 1998;160(7):3513-3521.

82. Uluçkan Ö, et al. Chronic skin inflammation leads to bone loss by IL-17-mediated inhibition of Wnt signaling in osteoblasts. Sci Transl Med. 2016;8(330):330ra37.

83. Kocijan R, Finzel S, Englbrecht M, Engelke K, Rech J, Schett G. Differences in bone structure between rheumatoid arthritis and psoriatic arthritis patients relative to autoantibody positivity. Ann Rheum Dis. 2014;73(11):2022-2028.

84. Haringman JJ, et al. Synovial tissue macrophages: a sensitive biomarker for response to treatment in patients with rheumatoid arthritis. Ann Rheum Dis. 2005;64(6):834-838.

85. Wei S, Wang MW, Teitelbaum SL, Ross FP. Interleukin-4 reversibly inhibits osteoclastogenesis via inhibition of NF- $\mathrm{kB}$ and mitogen-activated protein kinase signaling. J Biol Chem. 2002;277(8):6622-6630.

86. Chen Z, et al. Th2 and eosinophil responses suppress inflammatory arthritis. Nat Commun. 2016;7:11596.

87. Kratochvill F, et al. TNF counterbalances the emergence of M2 tumor macrophages. Cell Rep. 2015;12(11):1902-1914.

88. Charles JF, Hsu LY, Niemi EC, Weiss A, Aliprantis AO, Nakamura MC. Inflammatory arthritis increases mouse osteoclast precursors with myeloid suppressor function. JClin Invest. 2012;122(12):4592-4605.

89. Zaiss MM, et al. Treg cells suppress osteoclast formation: a new link between the 
immune system and bone. Arthritis Rheum 2007;56(12):4104-4112.

90. Sharma K. IL-18 attenuates experimental choroidal neovascularization as a potential therapy for wet age-related macular degeneration. Ann Neurosci. 2014;21(4):150.

91. Gao Y, et al. Inflammation negatively regulates FOXP3 and regulatory T-cell function via DBC1. Proc Natl Acad Sci U S A. 2015;112(25):E3246-E3254.

92. Buchwald ZS, Kiesel JR, DiPaolo R, Pagadala MS, Aurora R. Osteoclast activated FoxP3 ${ }^{+} \mathrm{CD}^{+}$ $\mathrm{T}$-cells suppress bone resorption in vitro. PLoS One. 2012;7(6):e38199.

93. Buchwald ZS, Kiesel JR, Yang C, DiPaolo R, Novack DV, Aurora R. Osteoclast-induced Foxp $3^{+}$CD8 T-cells limit bone loss in mice. Bone. 2013;56(1):163-173.

94. Shashkova EV, et al. Osteoclast-primed Foxp $3^{+}$ CD8 T cells induce T-bet, Eomesodermin, and IFN- $\gamma$ to regulate bone resorption. JImmunol. 2016;197(3):726-735.

95. Kong YY, et al. Activated T cells regulate bone loss and joint destruction in adjuvant arthritis through osteoprotegerin ligand. Nature. 1999;402(6759):304-309.

96. Kotake S, et al. IFN- $\gamma$-producing human T cells directly induce osteoclastogenesis from human monocytes via the expression of RANKL. Eur J Immunol. 2005;35(11):3353-3363.

97. Gao Y, et al. IFN- $\gamma$ stimulates osteoclast formation and bone loss in vivo via antigen-driven $\mathrm{T}$ cell activation. J Clin Invest. 2007;117(1):122-132.

98. Bonar SL, et al. Constitutively activated NLRP3 inflammasome causes inflammation and abnormal skeletal development in mice. PLoS One. 2012;7(4):e35979.

99. Qu C, et al. NLRP3 mediates osteolysis through inflammation-dependent and -independent mechanisms. FASEB J. 2015;29(4):1269-1279.

100.McCall SH, et al. Osteoblasts express NLRP3, a nucleotide-binding domain and leucine-rich repeat region containing receptor implicated in bacterially induced cell death.J Bone Miner Res. 2008;23(1):30-40.

101.Feldmann J, et al. Chronic infantile neurological cutaneous and articular syndrome is caused by mutations in CIAS1, a gene highly expressed in polymorphonuclear cells and chondrocytes. Am J Hum Genet. 2002;71(1):198-203.

102. Martinon F, Burns K, Tschopp J. The inflammasome: a molecular platform triggering activation of inflammatory caspases and processing of proIL-beta. Mol Cell. 2002;10(2):417-426.

103. Guo H, Callaway JB, Ting JP. Inflammasomes: mechanism of action, role in disease, and therapeutics. Nat Med. 2015;21(7):677-687.

104.Lukens JR, Gross JM, Kanneganti TD. IL-1 family cytokines trigger sterile inflammatory disease. Front Immunol. 2012;3:315.

105. Martin SJ. Cell death and inflammation: the case for IL-1 family cytokines as the canonical DAMPs of the immune system. FEBS J. 2016;283(14):2599-2615.

106. Malireddi RK, Ippagunta S, Lamkanfi M, Kanneganti TD. Cutting edge: proteolytic inactivation of poly(ADP-ribose) polymerase 1 by the Nlrp3 and Nlrc4 inflammasomes. JImmunol.
2010;185(6):3127-3130.

107. Wang C, et al. Poly-ADP-ribosylation-mediated degradation of ARTD1 by the NLRP3 inflammasome is a prerequisite for osteoclast maturation. Cell Death Dis. 2016;7:e2153.

108.Erener S, et al. Inflammasome-activated caspase 7 cleaves PARP1 to enhance the expression of a subset of NF-кB target genes. Mol Cell. 2012;46(2):200-211.

109. Martinon F, Pétrilli V, Mayor A, Tardivel A, Tschopp J. Gout-associated uric acid crystals activate the NALP3 inflammasome. Nature. 2006;440(7081):237-241.

110. Rosengren S, Hoffman HM, Bugbee W, Boyle DL. Expression and regulation of cryopyrin and related proteins in rheumatoid arthritis synovium. Ann Rheum Dis. 2005;64(5):708-714.

111. Kolly L, Busso N, Palmer G, Talabot-Ayer D, Chobaz V, So A. Expression and function of the NALP3 inflammasome in rheumatoid synovium. Immunology. 2010;129(2):178-185.

112. Beranger GE, et al. RANKL treatment releases the negative regulation of the poly(ADP-ribose) polymerase-1 on Tcirg1 gene expression during osteoclastogenesis. JBone Miner Res. 2006;21(11):1757-1769.

113. Beranger GE, Momier D, Rochet N, Carle GF, Scimeca JC. Poly(adp-ribose) polymerase-1 regulates Tracp gene promoter activity during RANKL-induced osteoclastogenesis. J Bone Miner Res. 2008;23(4):564-571.

114. Robaszkiewicz A, et al. ARTD1 regulates osteoclastogenesis and bone homeostasis by dampening NF- $\mathrm{kB}$-dependent transcription of IL-1 $1 \beta$. S $c i$ Rep. 2016;6:21131.

115. Hoffman HM, Broderick L. The role of the inflammasome in patients with autoinflammatory diseases. JAllergy Clin Immunol. 2016;138(1):3-14.

116. Aksentijevich I, et al. De novo CIAS1 mutations, cytokine activation, and evidence for genetic heterogeneity in patients with neonatal-onset multisystem inflammatory disease (NOMID): a new member of the expanding family of pyrin-associated autoinflammatory diseases. Arthritis Rheum. 2002;46(12):3340-3348.

117. Zaki FM, Sridharan R, Pei TS, Ibrahim S, Ping TS. NOMID: the radiographic and MRI features and review of literature. J Radiol Case Rep. 2012;6(3):1-8.

118. Hill SC, Namde M, Dwyer A, Poznanski A, Canna S, Goldbach-Mansky R. Arthropathy of neonatal onset multisystem inflammatory disease (NOMID/CINCA). Pediatr Radiol. 2007;37(2):145-152.

119. Anton J, et al. Efficacy and safety of canakinumab in cryopyrin-associated periodic syndromes: results from a Spanish cohort. Clin Exp Rheumatol. 2015;33(6 suppl 94):S67-S71.

120. Sibley $\mathrm{CH}$, et al. Sustained response and prevention of damage progression in patients with neonatal-onset multisystem inflammatory disease treated with anakinra: a cohort study to determine three- and five-year outcomes. Arthritis Rheum. 2012;64(7):2375-2386.

121. Neven B, et al. Long-term efficacy of the interleukin-1 receptor antagonist anakinra in ten patients with neonatal-onset multisystem inflammatory disease/chronic infantile neurologic, cutaneous, articular syndrome. Arthritis Rheum. 2010;62(1):258-267.

122. Rigante D, Leone A, Marrocco R, Laino ME, Stabile A. Long-term response after 6-year treatment with anakinra and onset of focal bone erosion in neonatal-onset multisystem inflammatory disease (NOMID/CINCA). Rheumatol Int. 2011;31(12):1661-1664.

123. Snouwaert JN, et al. An NLRP3 mutation causes arthropathy and osteoporosis in humanized mice. Cell Rep. 2016;17(11):3077-3088.

124.Zhao Y, et al. The NLRC4 inflammasome receptors for bacterial flagellin and type III secretion apparatus. Nature. 2011;477(7366):596-600.

125. Canna SW, Nigrovic PA. Editorial: 21st century storm chasers: defining macrophage activation syndrome. Arthritis Rheumatol. 2016;68(3):557-560.

126. Romberg N, et al. Mutation of NLRC4 causes a syndrome of enterocolitis and autoinflammation. Nat Genet. 2014;46(10):1135-1139.

127. Canna SW, et al. An activating NLRC4 inflammasome mutation causes autoinflammation with recurrent macrophage activation syndrome. Nat Genet. 2014;46(10):1140-1146.

128. Bechtold S, Simon D. Growth abnormalities in children and adolescents with juvenile idiopathic arthritis. Rheumatol Int. 2014;34(11):1483-1488.

129. Maruotti N, Corrado A, Cantatore FP. Osteoporosis and rheumatic diseases. Reumatismo. 2014;66(2):125-135.

130. Kitamura A, Sasaki Y, Abe T, Kano H, Yasutomo K. An inherited mutation in NLRC4 causes autoinflammation in human and mice. J Exp Med. 2014;211(12):2385-2396.

131. Ozen S, Bilginer Y. A clinical guide to autoinflammatory diseases: familial Mediterranean fever and next-of-kin. Nat Rev Rheumatol. 2014;10(3):135-147.

132. Ben-Zvi I, Livneh A. Chronic inflammation in FMF: markers, risk factors, outcomes and therapy. Nat Rev Rheumatol. 2011;7(2):105-112.

133. Ben-Zvi I, et al. Anakinra for colchicine resistant familial Mediterranean fever - a randomized, double blind, placebo-controlled trial. Arthritis Rheumatol.2017;69(4):854-862.

134. Chae JJ, et al. Gain-of-function Pyrin mutations induce NLRP3 protein-independent interleukin- $1 \beta$ activation and severe autoinflammation in mice. Immunity. 2011;34(5):755-768.

135. Hofmann SR, Schnabel A, Rösen-Wolff A, Morbach H, Girschick HJ, Hedrich CM. Chronic nonbacterial osteomyelitis: pathophysiological concepts and current treatment strategies. JRheumatol. 2016;43(11):1956-1964.

136. Scianaro R, et al. Deregulation of the IL-1 $\beta$ axis in chronic recurrent multifocal osteomyelitis. Pediatr Rheumatol Online J. 2014;12:30.

137. Chitu V, et al. PSTPIP2 deficiency in mice causes osteopenia and increased differentiation of multipotent myeloid precursors into osteoclasts. Blood. 2012;120(15):3126-3135.

138. Cassel SL, et al. Inflammasome-independent IL-1 $\beta$ mediates autoinflammatory disease in Pstpip2-deficient mice. Proc Natl Acad Sci U S A. 2014;111(3):1072-1077.

139. Lukens JR, et al. Critical role for inflammasome-independent IL-1 $1 \beta$ production 
in osteomyelitis. Proc Natl Acad Sci U S A. 2014;111(3):1066-1071.

140. Gurung P, Burton A, Kanneganti TD. NLRP3 inflammasome plays a redundant role with caspase 8 to promote IL-1 $\beta$-mediated osteomyelitis. Proc Natl Acad Sci U S A . 2016;113(16):4452-4457.

141. Cobelli N, Scharf B, Crisi GM, Hardin J, Santambrogio L. Mediators of the inflammatory response to joint replacement devices. Nat Rev Rheumatol. 2011;7(10):600-608.

142.Abu-Amer Y, Darwech I, Clohisy JC. Aseptic loosening of total joint replacements: mechanisms underlying osteolysis and potential therapies. Arthritis Res Ther. 2007;9 Suppl 1:S6.

143. Burton L, et al. Orthopedic wear debris mediated inflammatory osteolysis is mediated in part by NALP3 inflammasome activation. JOrthop Res. 2013;31(1):73-80.

144.Caicedo MS, Samelko L, McAllister K, Jacobs JJ, Hallab NJ. Increasing both CoCrMo-alloy particle size and surface irregularity induces increased macrophage inflammasome activation in vitro potentially through lysosomal destabilization mechanisms. JOrthop Res. 2013;31(10):1633-1642.

145. Maitra R, et al. Endosomal damage and TLR2 mediated inflammasome activation by alkane particles in the generation of aseptic osteolysis. Mol Immunol. 2009;47(2-3):175-184.

146. Naganuma Y, et al. Lipoteichoic acid modulates inflammatory response in macrophages after phagocytosis of titanium particles through Tolllike receptor 2 cascade and inflammasomes. J Biomed Mater Res A. 2016;104(2):435-444.

147. Samelko L, Landgraeber S, McAllister K, Jacobs J, Hallab NJ. Cobalt alloy implant debris induces inflammation and bone loss primarily through danger signaling, not TLR4 activation: implications for DAMP-ening implant related inflammation. PLoS One. 2016;11(7):e0160141.

148. Christo SN, et al. Inflammasome components ASC and AIM2 modulate the acute phase of biomaterial implant-induced foreign body responses. Sci Rep. 2016;6:20635.

149. Birt MC, Anderson DW, Bruce Toby E, Wang J. Osteomyelitis: recent advances in pathophysiology and therapeutic strategies. JOrthop. 2017;14(1):45-52.

150. Josse J, et al. Impact of the maturation of human primary bone-forming cells on their behavior in acute or persistent Staphylococcus aureus infection models. Front Cell Infect Microbiol. 2016;6:64.

151. Dapunt U, Maurer S, Giese T, Gaida MM, Hänsch GM. The macrophage inflammatory proteins MIP1 $\alpha$ (CCL3) and MIP2 $\alpha$ (CXCL2) in implant-associated osteomyelitis: linking inflammation to bone degradation. Mediators Inflamm. 2014;2014:728619.

152. Grundmeier M, et al. Staphylococcal strains vary greatly in their ability to induce an inflammatory response in endothelial cells. J Infect Dis. 2010;201(6):871-880.

153. Yoshii T, et al. Local levels of interleukin-1 $\beta,-4$, -6 and tumor necrosis factor $\alpha$ in an experimental model of murine osteomyelitis due to staphylococcus aureus. Cytokine. 2002;19(2):59-65.

154.Sultana S, Adhikary R, Nandi A, Bishayi B. Neutralization of MMP-2 protects Staphylococcus aureus infection induced septic arthritis in mice and regulates the levels of cytokines. Microb Pathog. 2016;99:148-161.

155. Holzinger D, et al. Staphylococcus aureus Panton-Valentine leukocidin induces an inflammatory response in human phagocytes via the NLRP3 inflammasome. J Leukoc Biol. 2012;92(5):1069-1081.

156. Craven RR, et al. Staphylococcus aureus alpha-hemolysin activates the NLRP3-inflammasome in human and mouse monocytic cells. PLoS One. 2009;4(10):e7446.

157. Muñoz-Planillo R, Franchi L, Miller LS, Núñez G. A critical role for hemolysins and bacterial lipoproteins in Staphylococcus aureus-induced activation of the Nlrp3 inflammasome. J Immunol. 2009;183(6):3942-3948.

158. Kinoshita T, Imamura R, Kushiyama H, Suda T. NLRP3 mediates NF- $\kappa$ B activation and cytokine induction in microbially induced and sterile inflammation. PLoS One. 2015;10(3):e0119179.

159. Kassem A, Lindholm C, Lerner UH. Toll-like receptor 2 stimulation of osteoblasts mediates Staphylococcus aureus induced bone resorption and osteoclastogenesis through enhanced RANKL. PLoS One. 2016;11(6):e0156708.

160. Krauss JL, Zeng R, Hickman-Brecks CL, Wilson JE, Ting JP, Novack DV. NLRP12 provides a critical checkpoint for osteoclast differentiation. Proc Natl Acad Sci U S A. 2015;112(33):10455-10460.

161. Claro T, Widaa A, McDonnell C, Foster TJ, O'Brien FJ, Kerrigan SW. Staphylococcus aureus protein A binding to osteoblast tumour necrosis factor receptor 1 results in activation of nuclear factor $\kappa \mathrm{B}$ and release of interleukin- 6 in bone infection. Microbiology. 2013;159(pt 1):147-154.

162. Chen Q, Hou T, Luo F, Wu X, Xie Z, Xu J. Involvement of toll-like receptor 2 and pro-apoptotic signaling pathways in bone remodeling in osteomy elitis. Cell Physiol Biochem. 2014;34(6):1890-1900.

163. Sanchez CJ, et al. Staphylococcus aureus biofilms decrease osteoblast viability, inhibits osteogenic differentiation, and increases bone resorption in vitro. BMC Musculoskelet Disord. 2013;14:187.

164. Young AB, Cooley ID, Chauhan VS, Marriott I. Causative agents of osteomyelitis induce death domain-containing TNF-related apoptosisinducing ligand receptor expression on osteoblasts. Bone. 2011;48(4):857-863.

165. Hajishengallis G, et al. Low-abundance biofilm species orchestrates inflammatory periodontal disease through the commensal microbiota and complement. Cell Host Microbe. 2011;10(5):497-506.

166. Hiramine H, Watanabe K, Hamada N, Umemoto $\mathrm{T}$. Porphyromonas gingivalis $67-\mathrm{kDa}$ fimbriae induced cytokine production and osteoclast differentiation utilizing TLR2. FEMS Microbiol Lett. 2003;229(1):49-55.

167. Prates TP, et al. NOD2 contributes to Porphyromonas gingivalis-induced bone resorption. J Dent Res. 2014;93(11):1155-1162.

168. Kassem A, Henning P, Lundberg P, Souza PP, Lindholm C, Lerner UH. Porphyromonas gingivalis stimulates bone resorption by enhancing RANKL (receptor activator of NF- $\kappa \mathrm{B}$ ligand) through activation of toll-like receptor 2 in osteoblasts. J Biol Chem. 2015;290(33):20147-20158. 169.Lin D, et al. IL-17 regulates the expressions of
RANKL and OPG in human periodontal ligament cells via TRAF6/TBK1-JNK/NF- $\kappa$ B pathways. Immunology. 2015;144(3):472-485.

170. Fitzpatrick RE, et al. The gingipains from Porphyromonas gingivalis do not directly induce osteoclast differentiation in primary mouse bone marrow cultures. J Periodont Res. 2009;44(4):565-567.

171. Akiyama T, et al. Porphyromonas gingivalis-derived lysine gingipain enhances osteoclast differentiation induced by tumor necrosis factor- $\alpha$ and interleukin- $1 \beta$ but suppresses that by interleukin-17A: importance of proteolytic degradation of osteoprotegerin by lysine gingipain. J Biol Chem. 2014;289(22):15621-15630.

172. Cohen SB, et al. Denosumab treatment effects on structural damage, bone mineral density, and bone turnover in rheumatoid arthritis: a twelvemonth, multicenter, randomized, double-blind, placebo-controlled, phase II clinical trial. Arthritis Rheum. 2008;58(5):1299-1309.

173. Schett G, Gravallese E. Bone erosion in rheumatoid arthritis: mechanisms, diagnosis and treatment. Nat Rev Rheumatol. 2012;8(11):656-664.

174. van der Heijde D, et al. Brief report: secukinumab provides significant and sustained inhibition of joint structural damage in a phase III study of active psoriatic arthritis. Arthritis Rheumatol. 2016;68(8):1914-1921.

175. Kavanaugh A, et al. Ustekinumab, an antiIL-12/23 p40 monoclonal antibody, inhibits radiographic progression in patients with active psoriatic arthritis: results of an integrated analysis of radiographic data from the phase 3 , multicentre, randomised, double-blind, placebo-controlled PSUMMIT-1 and PSUMMIT-2 trials. Ann Rheum Dis. 2014;73(6):1000-1006.

176. Jiang Y, et al. A multicenter, double-blind, dose-ranging, randomized, placebo-controlled study of recombinant human interleukin-1 receptor antagonist in patients with rheumatoid arthritis: radiologic progression and correlation of Genant and Larsen scores. Arthritis Rheum. 2000;43(5):1001-1009.

177. Bardin T. Canakinumab for the patient with difficult-to-treat gouty arthritis: review of the clinical evidence. Joint Bone Spine. 2015;82 Suppl 1:eS9-e16.

178. Coll RC, et al. A small-molecule inhibitor of the NLRP3 inflammasome for the treatment of inflammatory diseases. Nat Med. 2015;21(3):248-255.

179. Bozec A, et al. T cell costimulation molecules CD80/86 inhibit osteoclast differentiation by inducing the IDO/tryptophan pathway. Sci Transl Med. 2014;6(235):235ra60.

180. Han X, et al. Porphyromonas gingivalis infection-associated periodontal bone resorption is dependent on receptor activator of NF- $\mathrm{BB}$ ligand. Infect Immun. 2013;81(5):1502-1509.

181. Yuan H, Gupte R, Zelkha S, Amar S. Receptor activator of nuclear factor kappa B ligand antagonists inhibit tissue inflammation and bone loss in experimental periodontitis. JClin Periodontol. 2011;38(11):1029-1036.

182. Jin Q, et al. RANKL inhibition through osteoprotegerin blocks bone loss in experimental periodontitis. J Periodontol. 2007;78(7):1300-1308.

183. Fabri GM, et al. Periodontitis response to antiTNF therapy in ankylosing spondylitis. J Clin Rheumatol. 2015;21(7):341-345. 